Losandro Antonio Tedeschi Universidade Federal da Grande Dourados, Dourados, MS, Brasil

\title{
Por uma história menor - uma análise deleuziana sobre a história das mulheres
}

Resumo: Para este artigo, escolhi o seguinte princípio analógico: se há uma "literatura menor", expressão que Deleuze e Guattari aplicam à obra de Franz Kafka, por que não pensarmos também em uma "história menor"? Com efeito, as narrativas femininas, marcadas por recortes memoriais, ao serem contadas, narradas e descritas, possibilitam o surgimento de discursos marginalizados e invisibilizados pela história tradicional. É essa história menor - essa memória feminina, assaz subjetiva, de cunho familiar, afetiva e maternal, bem como negligenciada pela memória oficial - que me proponho a analisar. Nessa perspectiva, a história do feminino, ao ser entendida como uma história menor, teria a força de produzir, através de linhas de fuga que ela própria constrói, descontinuidades na história oficial.

Palavras-chave: História das mulheres, história menor, gênero, memória

\section{Introdução}

As produções teóricas relativas à História das Mulheres estão ligadas ao movimento de renovação da própria história. Tal movimento - distanciando-se da história tradicional de cunho positivista dominante no século XIX - voltava a estar mais interessado no coletivo do que no individual, na evolução da sociedade do que nas instituições, nos costumes do que nos acontecimentos, nas coletividades excluídas do que nas grandes personagens. ${ }^{1}$

Esta obra está sob licença Creative Commons.

${ }^{1}$ A utilização que aqui se faz da expressão "história das mulheres" assume e representa algumas das múltiplas correntes e concepções existentes neste campo historiográfico, por exemplo, a tradicional e a positivista desde o seu significado original até as abordagens teóricas dos estudos feministas e da história do gênero não tendo por isso nenhuma conotação particular com alguma das correntes referidas anteriormente. É exatamente pela multiplicidade de correntes e abordagens que a História das Mulheres se firma profundamente no cenário epistemológico-contemporâneo. Opção semelhante foi tomada, por exemplo, na extensa obra História das Mulheres no Ocidente, dirigida por Georges DUBY e Michelle PERROT (1994). 
O nascimento de novas abordagens e perspectivas na história, ocorrido com a "fundação da escola dos Annales", em 1929, traz consigo uma agenda que conquistará um espaço fundamental para a emergência da história das mulheres, caracterizando-se pela crítica às narrativas históricas tradicionais (a história factual, em geral, e aquela política ou econômica, em particular), pela procura de colaboração com outras ciências ou pela substituição da história simplesmente narrada por uma história reflexiva, uma históriaproblema.

O estatuto marginal atribuído às mulheres pela abordagem crítica da história, por um lado, e a consciência de que a história de mulheres começava a se desenhar sobretudo no que se refere à ausência e ao silêncio que as envolvia -, por outro, levou o movimento feminista a lutar, desde a década de 1960, pela visibilidade das mulheres e pelo seu protagonismo na história. O silêncio e a ausência mencionada teriam, assim, de ser rompida através da militância no seio desse movimento, cujo intuito seria o de pôr em evidência o papel fundamental desempenhado pelas mulheres e as marcas por ele deixadas, as quais foram apagadas pela cultura androcêntrica no decurso dos acontecimentos históricos.

Margareth RAGO (2011), ao discorrer sobre as novas transformações no fazer historiográfico feminino, aponta que

\begin{abstract}
a partir da década de oitenta, na verdade, registra-se uma verdadeira explosão dos temas femininos, seja no campo da História Social, seja no da Nouvelle Histoire, abordando assuntos que vão desde a presença das mulheres nas greves, manifestações operárias e outras formas de luta social até a bruxaria, a prostituição, a loucura, o aborto, a maternidade e o parto, a saúde, a sexualidade, a história das emoções e dos sentimentos, para grande surpresa e insatisfação dos antigos historiadores, acostumados às questões econômicas e políticas de uma macro-história (p. 2).
\end{abstract}

Muito dos paradigmas que orientavam até então o fazer historiográfico estavam assentes no pressuposto de que a realidade era uma entidade objetiva e, portanto, a consciência, a identidade e as ações dos sujeitos históricos eram determinadas pelas condições materiais de existência. Um discurso como esse - racionalista, objetivista e à luz do qual as mulheres não tiveram participação de modo visível nos caminhos tradicionais do fazer histórico - representava a tradição e o cânone.

A teoria feminista procurou então investigar a fundamentação dessa ausência. 0 seu modo de teorização surge com pensadoras e revolucionárias, como, por exemplo, Mary WOLLSTONECRAFT (2016) e seus Escritos Políticos, nos quais criticava o sexismo de pensadores homens, como Rousseau), Rosa de LUXEMBURGO (2003) (com sua originalidade reflexiva acerca do socialismo alemão, o qual esteve presente até meados do século XX, inclusive nas concepções e práticas pedagógicas escolares) ou Simone de BEAUVOIR (2009) (e seu livro $O$ segundo sexo, através do qual alertava sobre os direitos das mulheres por meio da reivindicação do ser e do pensar a vida pública e o universo do discurso e do poder).

A crítica às narrativas históricas, introduzida sobretudo pelo feminismo, passa a mostrar que a própria história de mulheres não teria sido idêntica para todas as mulheres. Tal fato provocou novas cisões, não apenas em relação a certa história geral masculina, que excluía as mulheres, mas em relação à própria história das mulheres, a qual, sem questionar os pressupostos hegemônicos e totalizantes, oriundos do positivismo historicista, havia invisibilizado tanto as mencionadas narrativas como o protagonismo da mulher na sociedade (Joana Maria PEDRO e Rachel SOIHET, 2007).

O historiador francês Roger CHARTIER (1995) chamou a atenção para o perigo, por exemplo, de se investir na diferença entre os sexos como discurso explicativo universal; de 
se observar os usos sexualmente diferenciados dos modelos culturais comuns aos dois sexos; de se definir a natureza da diferença que marca a prática feminina; da incorporação feminina à dominação masculina que opera como uma máquina de territorialização e de definição de identidades de gênero.

A história como o lugar da legitimação, do domínio, fez com que Virginia WOOLF (1980), em sua célebre obra Um teto todo seu, apontasse uma dimensão profundamente importante da vida das mulheres: o espaço privado do quarto, das quatro paredes, como espaço constitutivo de identidades, resistências, sonhos e desilusões. O controle e a distribuição da palavra escrita-empregada principalmente por homens letrados, escritores, cronistas e historiógrafos - implicou o uso abusivo do poder simbólico de narrar, relatar e significar, com pretensa superioridade, determinados momentos da realidade ligados diretamente aos triunfos e aos grandes feitos heroicos.

No Brasil, Maria Odila Leite da SILVA DIAS (1983), após analisar as estratégias informais e silenciosas de mulheres da periferia de São Paulo no final do século XIX, abre caminho para uma história feita pelas fissuras, ao afirmar que havia

todo um caleidoscópio de pequenas referências esparsas, pingando em profusão das mais disparatadas fontes, atesta a sua presença ostensiva, porém de modo fragmentário, pouco deixando entrever sobre os seus modos de inserção na sociedade da época ( $p$. 34).

A história das mulheres se desenvolveu, dessa forma, aprisionada aos sólidos muros - e talvez intocáveis - do pensamento universal masculino, num território marcado pela exclusão das capacidades do humano. Como resultado, tal parcela da humanidade (mais da metade), miserável e confinada, não pôde sequer ser constituidora de sua própria memória. Esse longo processo histórico ficou então caracterizado, como reflexo direto das relações patriarcais de poder, pela desmemorização e descorporalização das mulheres.

Ao pensar a necessidade de outra História - bem como de outras histórias -, Walter BENJAMIN (1994) procurou traçar a trajetória de todos os excluídos e renegados, para dar conta de "um mundo das chancelarias e dos arquivos, das salas mofadas, escuras, decadentes" (p. 138) de onde emergem os maiores perdedores do século XX: os personagens do escritor tcheco Franz Kafka.

A possibilidade de uma outra história, calcada na utilização de uma língua "menor", passa a ser pensada, no entanto, a partir do que comentam Gilles DELEUZE e Félix GUATTARI (2014): "uma literatura [no nosso caso, uma história] menor não pertence a uma língua menor, mas, antes, à língua que uma minoria constrói numa língua maior".

É nessa impossibilidade de narrar, de não se deter o poder da narrativa, que reside a primeira característica essencial das línguas ou do termo "literaturas menores" (DELEUZE e GUATTARI, 2014, p. 38): há a impossibilidade de se falar na língua daquele que oprime, ou de se justificar uma narrativa histórica das relações entre os sexos a partir do olhar opressor; mas também há a impossibilidade de não se falar nesta narrativa, pelo próprio risco da censura, do não poder contar. É o mesmo espaço que a História destinou às mulheres: a cozinha, o quarto, os cantos, as cartas, os bordados, as frestas, as notas de rodapé. Esse foi, infelizmente, um requisito para que a história funcionasse através da memória e das narrativas tradicionais do patriarcado. Afinal, uma história fora da história tem relação direta com a perda da memória das mulheres e com a sua ausência no cenário humano.

Aqui, a tentativa é subverter a lógica; ou seja, são essas pequenas notas, esses fragmentos de sentimento que, num dizer uníssono, são capazes de suplantar a grande narrativa. Age-se, assim, sob suas falhas; questionam-se seus remendos num trabalho de Ariadne, que tece o fio que conduz à saída do labirinto; ou, como Franz KAFKA (2001), que 
busca, através de seus personagens, construir saídas através das frestas, dos sótãos, das brechas, dos buracos, das passagens, das tocas, para fazer existir um mundo que possa ser diferente daquele que ele não consegue suportar.

Devido ao espaço restrito deste ensaio, não pretendo oferecer uma cartografia do caráter "menor" na história das mulheres, mas sim promover um exercício de deslocamento conceitual: transferir a noção de "literatura menor", a partir das contribuições de Deleuze e Guattari, e operar com a noção de "história menor", seja pensando em outras reflexões possíveis na história das mulheres, seja ampliando o sentido de "menor" para além da condição de inferioridade e desvalorização.

O "menor" em Kafka, a partir de Deleuze e Guattari, permanece sempre singular, sem se tornar modelo para outras produções. Ele é a criação de uma diferença, uma singularização de sujeitos sem fama, que se fazem, se desfazem e se metamorfoseiam no processo histórico. Pensar em uma "história menor" no feminino, na perspectiva do que Deleuze e Guattari fizeram na obra Kafka: por uma literatura menor, é criar uma nova singularidade, é buscar outros olhares sobre o domínio das fontes (tão caras aos historiadores/ as) e outros agenciamentos coletivos de enunciação, a partir de sujeitos invisíveis na história e dos lugares que ocupam - lugares que a sociedade definiu, impôs e sedimentou.

\section{Em torno de uma história menor: deslocamentos conceituais para se pensar a história das mulheres}

Ao aventurar-me a fazer um deslocamento do conceito "literatura menor" para "história menor", no sentido deleuzo-guattariano, proponho um exercício que funciona como um devir, como uma criação, numa reflexão sobre a história das mulheres. Ao ampliar o sentido de "menor", ${ }^{2}$ indo além da condição de inferioridade e desvalorização das mulheres, estamos desconstruindo as noções essencialistas acerca dos gêneros na história. As grandes narrativas, os grandes textos da historiografia tradicional foram "canonizados e fecundados", bem como integrados pela posteridade a uma longa cadeia evolutiva e linear descrita/escrita no masculino, em nome da razão, da consciência, do poder, da colonização e da conquista.

Durante muito tempo foram negadas às mulheres a autonomia e a subjetividade necessárias à criação, consequência da manipulação e do controle tanto da palavra quanto da escrita. Isso assegurou a instalação do poder, da lei e do imaginário social na História (com H maiúsculo) e trouxe, como consequência, a legitimação de uma minoria social que assegurou, determinou e confinou as ferramentas do pensar, vedando às mulheres - livre exercício da autonomia do narrar e do escrever. O patriarcado teve, como uma de suas funções na história, a construção e a reprodução de uma memória implacável, imóvel, endurecida e controladora da episteme historiográfica.

A história oficial construiu uma narrativa legitimista sobre os conceitos de maior/ menor, intimamente vinculados aos mecanismos de seleção e exclusão operados pelas instâncias de legitimação da "verdade". Por conseguinte, os critérios balizadores dessa

\footnotetext{
2 "Menor" é aquela prática que assume sua marginalidade em relação aos papéis representativos e ideológicos da língua e que aceita o exílio no interior das práticas discursivas majoritárias, formulando-se como estrangeira na própria língua, gaguejando e deixando emergir o sotaque e o estranhamento de quem fala fora do lugar ou de quem aceita e assume o não lugar como seu deserto, na impossibilidade de uma origem. Assim, o escritor ou o artista não precisa efetivamente formar parte de uma minoria, basta "encontrar seu próprio ponto de subdesenvolvimento, seu próprio patoá, seu próprio terceiro mundo, seu próprio deserto" (DELEUZE, GUATTARI, 2014, p. 39) para assumir a prática menor. A dimensão positiva desta prática é que ela carrega em si uma comunidade possível ou um "povo por vir", segundo a formulação enigmática de Deleuze e Guattari. Ver: Karl Erik SCHOLLHAMMER (2001).
} 
seleção são predominantemente históricos, contingenciais, ocorridos em um determinado tempo e lugar. A história das mulheres, por sua vez, narra e revela uma "história menor", do silêncio, ${ }^{3}$ uma história do confinamento, arbitrária, cercada de mistérios e zonas de sombra.

O exercício que faremos aqui é subverter o conceito de "menor", tornando-o potente e compreendê-lo na história das mulheres como aquele que está abaixo da palavra de ordem e que se localiza fora das imagens impostas pela maioria. Salientamos que não se trata de uma ideia e de um exercício hermenêutico fundado no binarismo maior/menor, pois, na concepção deleuziana, o "menor" se realiza sempre dentro do maior, constituindose como estratégia geradora de tensão na língua maior.

Em Kafka: por uma literatura menor, Deleuze e Guattari (2014) realizam uma inversão do conceito "menor", entendendo "literatura menor" não como uma literatura de valor diminuído, mas como a língua de uma minoria diante de uma língua maior. Os autores, ao definirem sua motivação pela obra de Kafka, fazem-no procurando realizar uma leitura que se pretende estratégica. Por esse motivo, desmontam, como a uma máquina, a narrativa kafkiana, para logo remontá-la teoricamente, numa espécie de exercício hermenêutico cujo intuito é descobrir e articular seus meandros, agenciamentos e conexões.

Os autores franceses apontam três características principais a serem observadas para que possamos identificar uma "literatura menor". Uso-as aqui como base para a análise que pretendo realizar.

A primeira delas é o componente de "desterritorialização". Sobre isso, afirmam:

[...] a impossibilidade de escrever de outro modo que não em alemão é para os judeus de Praga o sentimento de uma irredutível distância com a territorialidade primitiva tcheca. E a impossibilidade de escrever em alemão é a desterritorialização da própria população alemã, minoria opressiva que fala uma língua cortada das massas, como uma "linguagem de papel" ou de artifício; com mais forte razão os judeus que, a um só tempo, fazem parte dessa minoria e são dela excluídos, tais como "ciganos tendo roubado a criança alemã no berço" (Idem, p. 35-36).

A ação de desterritorializar associa-se à problemática da literatura "menor", pois implica um deslocamento provocado pela descaracterização cultural em função do espaço e da língua falada por grupos ou subgrupos étnicos, raciais, sexuais ou culturais que, em dado momento histórico, acham-se submetidos a um processo de marginalização. Silvio GALLO (2002), a partir da concepção engendrada por Deleuze e Guattari (2014), ajuda a compreender que

toda língua tem sua territorialidade, está em certo território físico, em certa tradição, em certa cultura. Toda língua é imanente a uma realidade. A literatura menor subverte essa realidade, desintegra esse real, nos arranca desse território, dessa tradição, dessa cultura. Uma literatura menor faz com que as raízes aflorem e flutuem, escapando desta territorialidade forçada. Ela nos remete a buscas, a novos encontros e novas fugas. A literatura menor nos leva sempre a novos agenciamentos (p. 172).

A desterritorialização é o movimento pelo qual se abandona o território, "é a operação da linha de fuga" (DELEUZE e GUATARI, 1996, p. 224), e a reterritorialização é o movimento de construção do território. Abandonar o território é ir ao encontro do inesperado, do novo. Nesse sentido, tomando como exemplo essa primeira característica, pensar uma "história menor" é se desviar do padrão, extrapolar o critério de medida já conhecido. É criar o novo, de modo que impere a ausência de talentos, de cânones ou de qualquer tradição balizadora com a qual o/a historiador/a tenha de dialogar.

\footnotetext{
${ }^{3}$ Na acepção de Michele Perrot.
} 


\begin{abstract}
Jamais nos desterritorializamos sozinhos, mas no mínimo com dois termos: mão-objeto de uso, boca-seio, rosto-paisagem. E cada um dos dois termos se reterritorializa sobre o outro. De forma que não se deve confundir a reterritorialização com o retorno a uma territorialidade primitiva ou mais antiga: ela implica necessariamente um conjunto de artifícios pelos quais um elemento, ele mesmo desterritorializado, serve de territorialidade nova ao outro que também perdeu a sua. Daí todo um sistema de reterritorializações horizontais e complementares, entre a mão e a ferramenta, a boca e o seio (DELEUZE e GUATTARI, 1996, p. 41).
\end{abstract}

Assim, "uma literatura menor não é a de uma língua menor, mas antes o que uma minoria faz em uma língua maior" (DELEUZE e GUATTARI, 2014, p. 35). Ou seja, a "história menor" não seria a renúncia ao uso da história "maior", a oficial - e, consequentemente, a adoção da história das minorias, que seriam as narrativas das mulheres, negros, índios, à história padrão -, mas sim o que essa minoria faz dentro do instituído. A criação de uma subversão, de uma contestação, de uma fuga. Trata-se de diferenciar essa história oficial, comprometida com as representações de uma sociedade sexista e disciplinar, fazendo dela um uso menor. É desterritorializar a história maior, fugir, escapar do território oficializado, promovendo distorções dentro do código/norma, desnudando os silêncios, criando torções, deslizamentos, ruídos; enfim, entrando pelas fissuras.

Uma "história menor" e desterritorializada no feminino levanta as raízes que a prendem nas grandes políticas, nos grandes acontecimentos de fatos históricos canonizados como verdadeiros. Ela age como uma "história menor" no território amplo da história; ela é essa intensidade que atravessa, que cruza um modelo maior e recria, na história oficial, essa história que faz subverter e verter novas possibilidades de invenção: "ir sempre mais longe na desterritorialização [...] por força de sobriedade. Já que o vocabulário está dissecado, fazêlo vibrar em intensidade" (DELEUZE e GUATTARI, 2014, p. 39). A história das mulheres é uma fuga, "uma fuga é uma espécie de delírio. Delirar é exatamente sair dos eixos, como 'pirar'" (DELEUZE, 1998, p. 51). É livrar-se da carcaça de uma sociedade disciplinar.

A linha de fuga é uma desterritorialização. O Grande erro. O único erro seria acreditar que uma linha de fuga consiste em fugir da vida; a fuga para o imaginário ou para a arte. Fugir, porém ao contrário, é produzir algo real, criar vida, encontrar uma arma [...]. Fugir não é absolutamente renunciar a ações, nada mais ativo que uma fuga. É o contrário do imaginário. É igualmente fazer fugir, não obrigatoriamente os outros, mas fazer fugir algo, fazer fugir um sistema como se arrebenta um tubo... fugir é traçar uma linha, linhas, toda uma cartografia (DELEUZE, 1998, p. 48).

\title{
Construir linhas de fuga, fugir, seria
}

[...] perder sua estanqueidade ou sua clausura; esquivar, escapar. Se fugir é fazer fugir, é porque a fuga não consiste em sair da situação para ir embora, mudar de vida, evadirse pelo sonho ou ainda transformar a situação (este último caso é mais complexo, pois fazer a situação fugir implica obrigatoriamente uma redistribuição dos possíveis que desemboca - salvo repressão obtusa - numa transformação ao menos parcial, perfeitamente improgramável, ligada à imprevisível criação de novos espaços-tempos, de agenciamentos institucionais inéditos; em todo caso, o problema está na fuga, no percurso de um processo desejante, não na transformação cujo resultado só valerá, por sua vez, por suas linhas de fuga, e assim por diante). Portanto, trata-se de fato de uma saída, mas esta é paradoxal (François ZOURABICHVILI, 2004, p. 30).

A obra Um teto todo seu, de Virginia Woolf (1985), propõe "linhas de fuga" aos padrões do período, negando a dicotomia metafísica entre masculino e feminino, assim como procurando desconstruir os conceitos já estabelecidos e hierarquizados pelo 
eurocentrismo e pelo sexismo masculino. Woolf desconstrói, no que diz respeito ao sexo feminino, a crença acerca de uma verdade absoluta e universal. A desconstrução ${ }^{4}$ atua, justamente, sobre esses conceitos "universais", através, por exemplo, do esforço para fazer com que sua plateia e seus leitores entendam que tudo o que foi dito e o que está sendo dito é, na realidade, uma verdade provisória e localizada, inscrita como opinião.

Arlette FARGE (2011), ao falar sobre a história das mulheres, refere que em vários lugares - nos discursos, nas falas singulares, nas práticas sociais ou por baixo dos discursos - se encontram embutidas falas (ou a própria oralidade) cujo intuito não é ilustrar, mas provocar problemas, incitando a busca por outras fontes que se relacionem com o descontínuo (e, poder-se-ia dizer, com o menor, com uma história menor). A história deve fomentar novas questões, permitindo assim a observação da dor, do medo, dos sentimentos, das subjetividades (coisas consideradas como pertencentes ao campo da literatura). A opinião é um emaranhado de memórias, informações e saberes fabricados pelas falas, pelos ritos e mesmo pelo silêncio. Farge (2011) propõe o estudo da história a partir de suas descontinuidades, de seus fragmentos:

[...] e se parece existir assim uma cadeia de palavras, esta nada tem de linear nem de liso; é antes da ordem do esquartejamento, da individuação, tecendo uma estrutura trágica, dispersa nos acontecimentos e de falas de que podemos encontrar as condições de emergência (p. 89).

Assim, as linhas de fuga, dentro de uma história menor, levariam a novos agenciamentos, ${ }^{5}$ ou seja, à produção de realidade material ou imaterial, e não a uma verdade que representaria o real:

[...] é sempre o agenciamento que produz os enunciados [...] o enunciado é o produto de um agenciamento, sempre coletivo, que põe em jogo, em nós e fora de nós, populações, multiplicidades, territórios, devires, afetos, acontecimentos (DELEUZE, 1998, p. 43).

Quando os textos das mulheres negras e indígenas, por exemplo, são aceitos pela crítica e pelo público, suas histórias são sancionadas e começa-se a questionar os padrões construídos social e politicamente, como a noção da alteridade. O agenciamento desses sujeitos vistos como "outro" se dá por meio da palavra, do discurso, na esfera pública. As mulheres negras e indígenas passam a se evidenciar nos espaços até então hegemônicos, e é nessa conquista que as suas identidades se transformam em estratégia.

\footnotetext{
${ }^{4}$ De acordo com o livro De que amanhâ... Diálogo, publicado por Jacques Derrida e Elisabeth ROUDINESCO (2004), o termo desconstrução foi utilizado pela primeira vez por Derrida em 1967 em Da gramatologia, tendo sido tomado da arquitetura. "Significa a deposição ou decomposição de uma estrutura. Em sua definição derridiana, remete a um trabalho do pensamento inconsciente ("isso se desconstrói"), e que consiste em desfazer, sem nunca destruir um sistema de pensamento hegemônico ou dominante. Desconstruir é, de certo modo, resistir à tirania do Um, do logos da metafísica (ocidental) na própria linguagem que é enunciada, com a ajuda do próprio material deslocado, movido com fins de reconstruções cambiantes".

${ }^{5}$ Segundo Zourabichvili (2004), "dir-se-á portanto, numa primeira aproximação, que se está em presença de uma agenciamento todas as vezes em que pudermos identificar e descrever o acoplamento de um conjunto de relações materiais e de um regime de signos correspondente. Na realidade, a disparidade dos casos de agenciamento precisa ser ordenada do ponto de vista da imanência, a partir do qual a existência se mostra indissociável de agenciamentos variáveis e remanejáveis que não cessam de produzi-la. Mais do que a um uso equívoco, ela remete então a pólos do próprio conceito, o que interdita sobretudo qualquer dualismo do desejo e da instituição, do instável e do estável. Cada indivíduo deve lidar com esses grandes agenciamentos sociais definidos por códigos específicos, que se caracterizam por uma forma relativamente estável e por um funcionamento reprodutor: tendem a reduzir o campo de experimentação de seu desejo a uma divisão preestabelecida" (p. 10).
} 
Como mostram Deleuze e Guattari (2012), o poder de uma maioria somente se sustenta pelo senso comum, pois os indivíduos que compõem essa supremacia numérica a submetem a uma variação intensiva contínua. Por outro lado, cada um, potencialmente, é uma minoria que quer se libertar do jugo dessa supremacia.

O que define então uma minoria não é o número, são as relações interiores ao número. Uma minoria pode ser numerosa ou mesmo infinita; do mesmo modo uma maioria. 0 que as distingue é que a relação interior ao número constitui no caso de uma maioria um conjunto, finito ou infinito, mas sempre numerável, enquanto que a minoria se define como conjunto não numerável, qualquer que seja o número de seus elementos. O que caracteriza o inumerável não é nem o conjunto nem os elementos; é antes a conexão, o "e", que se produz entre os elementos, entre os conjuntos, e que não pertence a qualquer dos dois, que lhes escapa e constitui uma linha de fuga (DELEUZE e GUATTARI, 2012, p. 186)

Por isso, as minorias podem ser muito mais numerosas que a maioria, pois aquelas detêm o segredo de sustentação desta última. As minorias podem ser "multidões" cuja organização desestabiliza o consenso das maiorias e a sua ordem política. Por isso, desterritorializar é puxar, pela diferenciação na história das mulheres, outras possibilidades; é fazer da história das mulheres algo inusitado, novo; é criar os ruídos dos quais falam Deleuze e Guattari formando um devir-minoritário, ou "minoria como figura universal, ou devir de todo o mundo. Um devir mulher de nós todos, quer sejamos masculinos ou femininos. Um devir não-branco de nós todos, quer sejamos brancos, amarelos ou negros" (DELEUZE e GUATTARI, 2012, p. 187).

Segundo Hélio Rebello CARDOSO JR. (2012),

[...] minoria não representa apenas a expressão numérica daqueles grupos que não se enquadram no padrão estabelecido pelo senso comum da maioria, mas, intensivamente, minorias são a respiração vital da maioria, ou seja, elas formam um "devir-minoritário" que diz respeito a todos; até mesmo àqueles indivíduos que parecem encarnar o modelo de Alguém para a maioria e constroem sua variação em torno do padrão vigente (p. 24).

A segunda característica de uma "literatura menor" é o seu componente político, que se relaciona com o povo. Segundo Gallo (2002), "sua existência é política, seu ato de ser é antes de tudo um ato político em essência [...] para a literatura menor o próprio ato de existir é um ato político, revolucionário: um desafio ao sistema instituído" (p. 172), a partir do qual "seu espaço exíguo faz com que cada caso individual seja imediatamente ligado à política" (DELEUZE e GUATTARI, 2014, p. 36).

Como componente político, uma "história menor" está associada a um agenciamento, a um devir-minoritário que, ao traçar linhas de fuga, implica a desvalorização, a ausência, a marginalização e, consequentemente, como contraponto, a valorização de outras estéticas, ideias, narrativas ou, ainda, de outros/as autores/as. Aí reside a dimensão política que Deleuze e Guattari lhe atribuem: escapa de uma territorialidade forçada pelas relações de poder, levando a buscas, fissuras e fugas, possibilitando a invenção de novas forças e adquirindo um estatuto coletivo e público.

Ao falar sobre a história das mulheres e seus contextos de emergência e valorização no cenário atual, Françoise THÉBAUD (2013) nos adverte que

durante mucho tiempo la história, incluso la relacionada con la Escuela de Annales, se há descrito en masculino. Confundiendo, de buena fé, el hombre como ser sexuado (vir em latín) y el hombre como ser humano (homo), ésta se há presentado como una historia general, como un discurso de universalidade. El historiador-filósofo no há percebido 
la importância y efectos de la diferencia de los sexos. El historiador ciudadano no há concedido lugar alguno a las que, durante mucho tiempo, fueron consideradas inaptas para la cidadania (p. 58).

Para a história oficial, o acontecimento histórico que envolvia o feminino estava em segundo plano, já que vinculado aos afetos, ao privado e ao subjetivo. Essa memória, essa experiência feminina, transmitida mesmo em silêncio, escapou de uma territorialidade marcada pelo poder masculino e possibilitou que essas narrativas menores pudessem construir um devir político, engendrando a construção de uma enunciação coletiva que se fez não por questões de consciência nacional, mas sim por múltiplas solidariedades entre as solitárias, as renegadas e as não cidadãs.

Margareth Rago (2015) pontua, a partir da historiografia feminista, que se iniciou uma operação e uma des-hierarquização dos acontecimentos:

[...] Todos se tornam passíveis de serem historicizados, e não apenas as ações de determinados sujeitos sociais, sexuais e étnicos das elites econômicas e políticas, ou de outros setores sociais, como o proletariado-masculino branco, tido como sujeito privilegiado por longo tempo na produção acadêmica. Aliás, as práticas passam a ser privilegiadas em relação aos sujeitos sociais, num movimento que me parece bastante democratizador (p. 5).

Como afirmam Deleuze e Guattari, Kafka, ao ampliar a narrativa para além de um narrador ou um personagem - estendendo-a a um grupo de solitários -, escreve para "esse povo que falta" (DELEUZE, 1998, p. 15), esse grupo reunido sob fronteiras que se dilatam e se estendem pelo tempo e pelo espaço. Tratam assim os autores das diferenças produzidas na e pela escrita de Kafka.

Ao trazermos essa análise para o campo das narrativas femininas, vamos aos poucos mostrando que as suas histórias não dizem respeito somente ao espaço privado, aos casos de amor, aos cuidados da família, ao servir, ao nutrir e às regras de etiqueta. Não; há uma outra história agitando-se dentro de uma história maior; uma condição de invisibilidade e de miséria (seja ela qual for); uma condição política, cultural, econômica, social, sexual, dentre outras. Há uma potencialidade política, um devir político, uma "história menor" que, quando vista pelo microscópico, não revela apenas casos universais, mas conflitos de gênero que envolvem, de forma complexa, as representações sociais que produziram seus corpos e suas subjetividades no decorrer da história.

As mulheres, ao escreverem sua história, sendo ousadas e recatadas, desbocadas e pudicas, sexuais e etéreas, passam a desenhar um devir político como potência. Usam seus lugares como potência inventiva - a potência de um pensamento "nômade", aberto às conexões, que se desvia dos processos de subjetivação manipulantes e ditantes de regras e condutas do patriarcado. São gestos e movimentos políticos que, por menores que sejam, escapam pelas frestas e pelos desvios de que nos fala Kafka, e insistem em produzir novos modos de se conduzirem, de se governarem a si mesmos, de criarem estratégias como ato político. Funda-se assim um pensamento menor feminino, isto é, um pensamento da resistência que se inventa no imprevisível, numa "história menor" de fugas-intensivas.

Uma "história menor", portanto, afina-se com o "menor" kafkiano em sua ramificação política. Segundo Gallo (2013),

a enunciação em uma literatura como a de Kafka não é produção de um indivíduo, de um sujeito autocentrado, como pensado na modernidade; ela é, de outro lado, uma produção coletiva, um amálgama de anseios, pensamentos, produções coletivas que se singularizam na produção do escritor. É uma forma coletiva de agenciar a enunciação destas percepções e afecções. E, por essa razão, a literatura menor possui uma 
ramificação políica, na medida em que ela é a tomada pública de palavra por um grupo social que até então não fazia uso dela. No caso de Kafka, sua literatura, como agenciamento coletivo de enunciação, é a voz dos judeus do gueto de Praga, que promovem uma desterritorialização da língua alemã que eles falam, "poluída" pelo í́diche, pelas expressões das ruas, criando linhas de fuga e tomando publicamente a palavra, fazendo ouvir uma voz que até então não se ouvia (p. 4).

A "história menor" torna imprescindíveis os pequenos artifícios, as proposições menores e - por que não? - as inutilidades dadas pelo discurso hegemônico. Esse processo de singularização, derivado de um todo, faz explodir narrativas, bem como memórias menores, subalternas ${ }^{6}$ e múltiplas, quando vistas segundo a perspectiva de outros sujeitos.

Como é possível pensar, criar, fazer e existir uma outra história que está encoberta pela história universal? O que pode a história das mulheres? Pensar pelas vias de uma "história menor" é atentar para as possibilidades, transformando as pequenas experimentações em resistências femininas que subvertem as relações de poder. Deleuze aponta que o desvio diante do que é majoritário é a vantagem que se apresenta ao menor. Aí está a importância qualitativa da minoria: desviar-se do padrão, desrespeitar o critério de medida estabelecido e interiorizado historicamente como natural. É criar o novo e promover o deslocamento.

Na história maior, perde-se a noção de contexto para se pensar um ambiente que funciona quase como um cenário, um mosaico que forma um todo. Já na "história menor", o que faz vibrar é uma política, uma ação dentro, com e a partir de um contexto. Não há aí uma história universal descolada das condições e do meio que a produz, pois, em uma história menor, "o caso individual se torna então mais necessário, indispensável, aumentado no microscópio, na medida em que uma outra história se agita nele" (DELEUZE e GUATTARI, 2014, p. 26).

A singularidade feminina comporta uma pluralidade que a constitui. A história menor torna visível - e sensível - esta multiplicidade, constituindo um ato político, como o fez/faz o movimento feminista. Estas histórias existem por meio de atos de resistência, de força política e de contestação. Nesse sentido, a história das mulheres está traçada não apenas pelo consentimento, ${ }^{7}$ mas também pela resistência frente aos dispositivos de poder que normalizam e disciplinam. Segundo Michel FOUCAULT (1999),

esses pontos de resistência estão presentes em toda a rede de poder [...] Resistências, no plural, que são casos únicos: possíveis, necessárias, improváveis, espontâneas, selvagens, solitárias, planejadas, arrastadas, violentas, irreconciliáveis, prontas ao compromisso, interessadas ao fadadas ao sacrifício [...] focos de resistência disseminamse com mais ou menos densidade no tempo e no espaço, às vezes provocando o levante de grupos ou indivíduos de maneira definitiva, inflamando certos pontos do corpo, certos momentos da vida, certos tipos de comportamento. Grandes rupturas radicais, divisões binárias e maciças? Às vezes. É mais comum, entretanto, serem pontos de resistência móveis e transitórios, que introduzem na sociedade clivagens que se deslocam, rompem unidades e suscitam reagrupamentos, percorrem os próprios indivíduos, recortando-os e os remodelando, traçando neles, em seus corpos e almas, regiões irredutíveis (p. 91-92).

É essa possibilidade - a de uma nova configuração de resistência feminina - que incide diretamente sobre a história e que nos leva a buscar, através desses pontos de fuga, as tramas da história, aquilo que Foucault chamou de saber, poder e subjetivação.

Michelle PERROT (2005), na introdução de sua obra As mulheres e os silêncios da história, provoca-nos da seguinte forma: "silenciosas as mulheres?". E completa: "o que

${ }^{6} \mathrm{Na}$ perspectiva de Gayatri Chakravorty SPIVAK.

${ }^{7}$ Na perspectiva de Geneviève FRAISSE (2012).

10 Revista Estudos Feministas, Florianópolis, 26(1): e46069 
fazer de uma história por meio da qual não sabemos nada delas?" (Idem, p. 9-10). Na perspectiva deleuziana, devemos traçar um plano micropolítico de revolução: não fazer, não dizer, burlar, deslizar, esquivar, silenciar, fazer de conta que não sabe e, quem sabe, não saber. Os atos menores, na história feminina, estão dotados de potência política quando empreendem uma guerrilha com os modos maiores e quando se expressam em desalinho com as objetivações universalizantes do discurso sobre os corpos, a sexualidade e a subjetividade das mulheres.

Deleuze e Guattari (2012), em Mil platôs, apontam-nos que o micropolítico como resistência é a vantagem que se apresenta ao menor. O qualitativo menor reside exatamente nos desvios em relação ao padrão, ao institucionalizado e àquilo que se estabeleceu como sendo "natural" na relação entre os sexos. O silêncio, neste contexto, seria então uma maneira de "desterritorialização" que irrompe na história e se impõe como fundamental na produção e na opção de uma estética do "menor", trazendo para o cotidiano a sensibilidade de uma micropolítica, de uma microrrevolução expressa nos gestos singulares do cotidiano de milhares de mulheres que lutam por respeito e dignidade em relação a seus corpos e suas mentes. ${ }^{8}$ coletivo:

A terceira característica do "menor", para Deleuze e Guattari (2014), é o seu valor

Não há sujeito, há apenas agenciamentos coletivos de enunciação - e a literatura exprime esses agenciamentos, nas condições em que eles não estão dados fora dela, e em que eles existem somente como potências diabólicas porvir ou como forças revolucionárias a construir.

A história das mulheres, como uma "história menor", é caracterizada pela partilha das multiplicidades. "Mesmo um agenciamento singular, fruto de um escritor, não pode ser visto como individual, pois o um que aí se expressa faz parte de muitos, e só pode ser visto como um se for identificado também como parte do todo coletivo", afirma Gallo (2008). E vai além: "[...] os valores deixam de pertencer e influenciar única e exclusivamente ao artista, para tomar conta de toda uma comunidade. O menor não fala por si mesmo, mas fala por milhares, por toda a coletividade. Os agenciamentos são coletivos" (p. 63).

As mulheres na história, ao falarem sobre si, sobre a morte, sobre a doença, sobre o amor, sobre a exclusão e as proibições, não escreveram sobre categorias universais. Escreveram sobre um processo múltiplo, que fez ligações com outros modos de vida de outras mulheres. Singularidades que, ao serem visibilizadas na lente do microscópio, possibilitam enxergar as complexas relações de gênero em que viviam. Elas não falam de si, mas sim a partir de situações compostas pelas multiplicidades de um contexto histórico, de uma situação ou, ainda, a partir de seus mundos e de suas circunstâncias. O sujeito dessa enunciação não está representado somente por elas, mas por várias, e por isso aquilo que escrevem e dizem assume um valor coletivo. seguinte:

No prefácio à edição italiana de Mil platôs, Deleuze e Guattari (2012) escreveram o

[...] as multiplicidades são a própria realidade, e não supõem nenhuma unidade, não entram em nenhuma totalidade e tampouco remetem a um sujeito. As subjetivações, as

\footnotetext{
${ }^{8} \mathrm{Na}$ atualidade, há uma nova cartografia de inquietudes que buscam repensar as temáticas clássicas do feminismo - o aborto, a sexualidade, o corpo, a violência, o acesso ao mercado de trabalho ou o trabalho do lar - em relação a outras problemáticas que antes não existiam. Assim, esses "novos" feminismos apontam para algumas das novas formas de dominação produzidas pelo patriarcado, assim como para a necessidade de colocar em marcha outras formas de expressão política e de resistência. Mostram, ainda, por outro lado, que o hiato da falta de memória histórica pode produzir grandes problemas ou ainda mais lacunas nos movimentos de mulheres ou nos novos feminismos.
} 


\begin{abstract}
totalizações, as unificações são, ao contrário, processos que se produzem e aparecem nas multiplicidades. Os princípios característicos das multiplicidades concernem a seus elementos, que são singularidades; a suas relações, que são devires; a seus acontecimentos, que são hecceidades (quer dizer, individuações sem sujeito); a seus espaços-tempos, que são espaços e tempos livres; a seu modelo de realização, que é o rizoma (por oposição ao modelo da árvore); a seu plano de composição, que constitui platôs (zonas de intensidade contínua); aos vetores que as atravessam, e que constituem territórios e graus de desterritorialização (DELEUZE e GUATARI, 2012, p. 10).
\end{abstract}

A história das mulheres, pensada como uma "história menor", é uma aposta nas múltiplas formas de narrar o feminino/a história como um rizoma que se conecta e se interconecta, gerando novas expressões múltiplas. Michelle Perrot (1995), ao falar sobre a história feminina, pontua que

[...] tratava-se inicialmente de tornar visível o que estava escondido, de reencontrar traços e de se questionar sobre as razões do silêncio que envolvia as mulheres enquanto sujeitos da história. Isso conduziu a uma reflexão em torno da história enquanto produto da dominação masculina, a qual atuava em dois níveis: nível dos próprios acontecimentos e nível da elaboração deles empreendida pelo relato (story e history) (p. 15).

Uma "história menor" é um ato de resistência que tem, no coletivo, o seu valor. As mulheres, principalmente aquelas que ousaram/ousam, através do movimento feminista e de outros movimentos, experimentar acontecimentos e vivências no campo da micropolítica - isto é, no campo do desejo, da autonomia, das linhas de fuga do instituído, da produção de novas subjetividades/subjetivações - não se sujeitam ao modelo binário ou patriarcal. Confrontam-se, pelo contrário, com uma outra história, uma nova fronteira, com linhas de fuga que traçam caminhos novos e inesperados no campo do desejo e da autonomia: uma espécie de devir-minoritário.

A história das mulheres como uma "história menor" seria uma espécie de lugar, de território marcado por processos de invenção ou experimentação, de movimentos de fuga às situações impostas pelo patriarcado que se materializam em ocorrências históricas individuais ou coletivas. O "menor" na história das mulheres é esse abrir-se às forças e linhas do devir que nos atravessam e que não têm princípio nem fim. Devir é estar "entre", é nomadizar, é sempre uma multiplicidade de fuga e, como tal, é uma "experimentaçãovida" (DELEUZE, 1998, p. 61).

\title{
Finalizando
}

Não foi objetivo deste artigo passar em revista o conceito de "literatura menor", 9 mas promover um exercício de deslocamento conceitual, operando com a noção de "história menor" como dispositivo que permitisse pensar a história das mulheres. O termo menor, uma criação da filosofia de Deleuze e Guattari (2014), é uma espécie de "conceito-adjetivo" usado em suas obras como uma ferramenta de análise.

Uma "história menor" é plural, múltipla. Ela não é única, são várias. Busca, em lugares diferentes, novas fontes e novas conexões, não se limitando a uma definição única. Deleuze e Guattari (2014) apontam que

trata-se de um devir que compreende, ao contrário, o máximo da diferença, como diferença de intensidade, atravessamento de um limiar, elevação ou queda, baixa ou ereção, acento de palavra. [...] não há mais sujeito de enunciação nem sujeito de

9 O/A leitor/a interessado/a na "literatura menor" pode recorrer ao próprio livro de Gilles Deleuze e Félix Guattari: Kafka por uma literatura menor.

12 Revista Estudos Feministas, Florianópolis, 26(1): e46069 
enunciado: não é mais o sujeito de enunciado que é um cão, o sujeito de enunciação permanecendo um "como" um homem [...] mas um circuito de estados que forma um devir mútuo, no seio de um agenciamento necessariamente múltiplo ou coletivo (p. 45).

A história das mulheres é marcada pelo movimento e tem, por referência, a não fixidez. Não é possível falar de uma "história menor" sob a perspectiva de uma totalidade, nem mesmo por mera transposição de algumas características do que possa vir a ser uma história das mulheres. É, pelo contrário, no campo dos usos e dos significados que a história precisa ser problematizada. O que é a história para as mulheres? Torna-se para quem é a história? O que é a história para mim, para o outro?

Ao deslocarmos o conceito de literatura menor que matiza essa discussão para o domínio da "história menor", fazemo-lo também como uma re-criação, uma desconstrução, uma ação por deslocamento - um "roubo" conceitual, como vim tentando desmontar, mantendo essas mesmas três características (desterritorialização, ramificação política e valor coletivo) presentes na obra de Deleuze e Guattari (2014).

Fui assim subvertendo, em um vai e vem de ideias, ressonâncias e contaminações, o que me fez desembocar no conceito de "história menor", uma concepção de história dada por outras vias de experimentação. E experimentar é arriscar-se. Como nos dizem Deleuze e Guattari (2014), "o castelo tem entradas múltiplas [...] é um rizoma, uma toca” (p. 09). Não há uma única porta de entrada; há várias, e nenhuma vale mais que a outra. Uma "história menor" considera a variedade e a variação das entradas, muitas vezes criando, ela mesma, portas de entrada e saída.

A história das mulheres como uma "história menor" toma em conta que o devir histórico não é processo de homogeneização, mas um discurso emaranhado de diferenciações, no qual cada fio segue, quebra, enreda, se perde em outro, mistura-se, "[...] como um cão que faz seu buraco, um rato que faz sua toca. E para isso, encontrar seus próprios pontos de subdesenvolvimento, seu próprio patoá, seu próprio terceiro mundo, seu próprio deserto" (DELEUZE e GUATTARI, 2014, p. 17).

Pensar a história das mulheres como uma "história menor" é buscar a des-totalização das experiências do sujeito universalizante masculino. Ser menor é plural, múltiplo. As práticas menores na história das mulheres não querem a oficialização, não querem o modelo. Elas estão mais voltadas para o campo das possibilidades, desequilibrando-se, marcadas por indecisões, rupturas e intervalos: o que pode alguma coisa?

O menor na história se exprime na multidão, nas fissuras do possível, e existe como força subterrânea, subalterna, marginal, caraterizada por fluxos contraditórios, divergentes, que proliferam e resistem à imposição de um discurso único sobre a verdade. Podemos supor que a história das mulheres, pensada na perspectiva do menor deleuziano, rompe com os muros do castelo de uma sociedade disciplinar, sexista e falogocêntrica.

É preciso fazermos experimentações na história das mulheres, com base naquilo que Deleuze e Guattari chamam de "pensamento nômade" (2012) - um pensar associado ao movimento fugidio, a uma "história menor" que escorrega, desvia e desliza, e que nos convida à vulnerabilidade de se largar o corpo e o pensamento, de deixar o pensamento alargar-se, para que se possa pensar de modo diferente em relação à forma como se pensa. Deleuze nos desafia, a nós, historiadores/as, sobretudo no que tange à criação, à experimentação e à invenção de [im]possibilidades. Convida-nos, assim, a construir uma história que veja o passado como capacidade inventiva a partir de outros sujeitos.

O discurso historiográfico não pode ser apaziguador, cristalizando o estabelecido como verdadeiro. Deve ser uma "narrativa solar que desconfia das sombras, que busca esclarecer e aclarar, que busca tornar visíveis os seres que ontem não passavam de sombras da caverna" (Durval Muniz ALBUQUERQUE, 2005, p. 47). A história das mulheres como uma 
história menor está situada no campo da destotalização, escondida nos espaços da desrazão, do silêncio, do instável e do inumano, desafiando-nos a um pensamento historiográfico indomado na acepção, tal como proposto por Deleuze e Foucault (RAGO, 1995).

Deleuze e Guattari mostram ainda que a vida não é feita somente de linhas duras; ela é também uma multiplicidade de linhas que correm, segmentarizam-se, entrelaçamse, multiplicam-se e se subtraem.

Na história das mulheres, é preciso atentar para o movimento destas linhas. Pedro e Soihet (2007) nos advertem sobre esses desafios que se impõem à história das mulheres e das relações de gênero:

Chegamos assim à atualidade, na qual a divergência de posições, os debates e controvérsias marcam o cenário; quadro que se nos afigura dos mais promissores, e que coincide com a diversidade de correntes presentes na historiografia atual. Diversidade que se manifesta na existência de vertentes que enxergam a teoria como ferramenta indispensável à construção do conhecimento histórico sobre as mulheres, até as que relativizam a sua presença, em nome do caráter fluido, ambíguo, do tema em foco: as mulheres como seres sociais. Ênfase na utilização da categoria 'gênero' na análise da esfera da política formal, em termos do exercício do voto e manejo do poder nas instituições do governo; preferência pela abordagem do cotidiano, "re-descoberta de papéis informais, de situações inéditas e atípicas" que possibilitem o desvendamento de processos sociais invisíveis, ante uma perspectiva normativa (p. 288).

O menor deleuziano que qualifica a história das mulheres está dotado da potência revolucionária de uma vida não fascista (RAGO e Alfredo VEIGA-NETO, 2009). Tal conceito visa a uma ruptura - como princípio de subversão da norma do impositivo que subtrai a história da lógica utilitarista, universalista e instrumentalizada.

Gilles Deleuze nos ensina que o menor é aquilo que permite dizer o seu tempo naquilo que não é, afirmando, desse modo, a inexorabilidade do processo histórico e, ao mesmo tempo, negando-o e fazendo a história de outra maneira.

Nessa perspectiva, deve-se pensar a "história menor" não no sentido de um grupo excluído da maioria ou subordinado a outro - por um padrão que define que a tal minoria sejam os negros, as mulheres ou os homossexuais -, mas no sentido de uma variação, escapando assim do sistema de poder pertencente à maioria. O menor seria, então, "um devir no qual nos engajamos" e cujo potencial criador e irruptivo estaria ligado à sua capacidade de não se render aos mecanismos de poder e de controle. Em suma, a resistência: manter-se vivo no deserto, como uma máquina de resistência.

A história das mulheres como "história menor" é a linha de fuga que impede que sejamos cooptados pelo poder. A opção pelo menor revela uma estratégia afirmativa, positiva e transformadora, com ênfase nas intensidades e nas fissuras da história. Compreendê-la, no seu potencial libertário, não apenas permite a autonomia, mas reafirma práticas que sempre foram, na história das mulheres, o reflexo de uma arte revolucionária, inventiva e, dentro das suas possibilidades, um importante marco de resistência.

A história das mulheres como uma "história menor" é, enfim, uma desbravadora de caminhos: abre brechas, fissuras e saliências; torna-nos revolucionários/as, conectandonos, conjugando-nos, reinventando-nos como sujeitos da história, com autonomia para além da moral, da opinião e dos poderes que nos produzem. A história das mulheres ocupa, dessa forma, esse lugar "impróprio", tolerado, conquistado, que escorrega pelos labirintos através do fio que conduz nossas vidas e memórias por caminhos até então inexistentes. É nessa potência do inexistente que reside a história das mulheres na perspectiva deleuziana, sempre por fazer-se, experimentando-se, recriando-se.

14 Revista Estudos Feministas, Florianópolis, 26(1): e46069 


\section{Referências}

ALBUQUERQUE, Júnior Durval Muniz de. A hora da estrela: a relação entre a história e a literatura, uma questão de gênero? In: XXIII SIMPÓSIO NACIONAL DE HISTÓRIA. Londrina, 2005.

BEAUVOIR. Simone De. O Segundo sexo. Rio de Janeiro: Nova Fronteira, 2009.

BENJAMIN, Walter. "O narrador: considerações sobre a obra de Nikolai Leskov". In: Obras escolhidas. São Paulo: Brasiliense, 1994.

CARDOSO Jr., Hélio Rebello. "Ontopolítica e diagramas históricos do poder: maioria e minoria segundo Deleuze e a teoria das multidões segundo Peirce". Revista Veritas, Porto Alegre, v. 57, n. 1, jan./abr. 2012.

CHARTIER, Roger. "Diferenças entre os sexos e dominação simbólica". Cadernos PAGU, Campinas, n. 4, 1995. (Nota crítica)

DELEUZE, Gilles; GUATTARI, Félix. Kafka: por uma literatura menor. Belo Horizonte: Autêntica, 2014.

Mil Platôs: capitalismo e esquizofrenia. Rio de Janeiro: Ed. 34, 1996. 3v.

Mil Platôs: capitalismo e esquizofrenia. São Paulo: Ed. 34, 2012. 5v.

DELEUZE, Gilles. "Uma conversa, o que é, para que serve?" In: DELEUZE, Gilles; PARNET, Claire. Diálogos. São Paulo: Escuta, 1998.

DERRIDA, Jacques; ROUDINESCO, Elisabeth. De que amanhã... Diálogo. Rio de Janeiro: Jorge Zahar, 2004.

DIAS, Maria Odila Leite da Silva. "Mulheres sem história". Revista de História, USP, n. 114, p. $31-45,1983$.

DUBY, Georges; PERROT, Michelle. A história das Mulheres no Ocidente. Lisboa: Afrontamento, 1994.

FOUCAULT, Michel. História da sexualidade. A vontade de saber. Rio de Janeiro: Graal, 1999.

FARGE, Arlette. Lugares para a História. Belo Horizonte: Autêntica, 2011 . (Coleção História e Historiografia).

FRAISSE, Geneviève. Del consentimiento. México: Universidad Nacional Autonoma del México; Programa Universitário de Estudios de Género (PUEG), 2012.

GALLO, Silvio. "Em torno de uma educação menor". Revista Educação e Realidade, EDUFGRS, v. 27, n. 2, p. 169-178, jul./dez. 2002.

Deleuze \& a educação. Belo Horizonte: Autêntica, 2008.

Em torno de uma educação menor: variáveis e variações. In: 36a REUNIÃO NACIONAL DA ANPED, Goiânia, 2013. Disponível em: http://36reuniao.anped.org.br/pdfs_trabalhos_ encomendados/gt13_trabencomendado_silviogallo.pdf. 2013. Acesso em 20/05/2016. KAFKA, Franz. A Metamorfose. São Paulo: Nova Alexandria, 2001.

LUXEMBURGO, Rosa de. Reforma ou revolução? São Paulo: Expressão Popular, 2003.

PEDRO, Joana Maria; SOIHET, Rachel. "A emergência da pesquisa da história das mulheres e das relações de gênero". Revista Brasileira de História, São Paulo, v. 27, n. 54, p. 281 $300,2007$.

PERROT, Michelle. As mulheres ou os silêncios da história. São Paulo: EDUSC, 2005.

. "Escrever uma história das mulheres: relato de uma experiência". Cadernos Pagu, n. 4, 1995

RAGO, Margareth e VEIGA-NETO, Alfredo (Orgs.). Para uma vida não-fascista. Belo Horizonte: Autêntica, 2009. (Coleção Estudos Foucaultianos)

RAGO, Margareth. Feminismos e História: um encontro com o passado. In: XXVI SIMPÓsIO NACIONAL DE HISTÓRIA - ANPUH, São Paulo. Anais... julho 2011.

"O efeito-Foucault na historiografia brasileira". Tempo Social, São Paulo, USP, v. 7, n. 1-2, p. 67-82, 1995. 
SCHOLLHAMMER; Karl Erik. "As práticas de uma língua menor: reflexões sobre um tema de Deleuze e Guattari". Ipotesi, Revista de Estudos Literários, Juiz de Fora, v. 5, n. 2, p. 59-70, 2001.

SPIVAK, Gayatri Chakravorty. Pode o subalterno falar? Belo Horizonte: EDUFMG, 2010.

THÉBAUD, Françoise. Escribir la historia de las mujeres y del género. Oviedo: KRK Ediciones, 2013.

WOLLSTONECRAFT, Mary. Reivindicação dos direitos da mulher. São Paulo: Boitempo, 2016. WOOLF, Virginia. Um teto todo seu. Rio de Janeiro: Nova Fronteira, 1985

ZOURABICHVILI, François. O vocabulário de Deleuze. Rio de Janeiro: IC, 2004. (Versão eletrônica)

[Recebido em 08/08/2016

e aprovado em 16/01/2017]

For a Smaller History - a Deleuzian Analysis About History of Women

Abstract: For this article, I chose the following analog principle: if there is a "minor literature", an expression that Deleuze and Guattari apply to the work of Franz Kafka, why not also think of a "minor history"? Indeed, the female narrative, marked by memorials clippings to be told, narrated and described, enable the emergence of marginalized and invisible speeches by traditional history. It is this smaller story - this female memory, rather subjective, family nature, emotional and maternal and neglected by official memory - I propose to analyze. In this perspective, the history of women, to be seen as a minor story, would have the power to produce, through lines of flight that builds itself, discontinuities in the official story.

Keywords: Women's history; Less history; Gender; Memory

Losandro Antonio Tedeschi (tedeschils@hotmail.com) é Professor Associado na Universidade Federal da Grande Dourados (UFGD). Áreas de ensino e pesquisa: Estudos de Gênero, História das Mulheres, Memória e Migrações. Participa como pesquisador do GT CLACSO Feminismos, Resistências e Processos Emancipatórios do grupo de investigação Fondo Cultural Frances da Universidade de Jaén (Espanha) na temática gênero e cultura.

16 Revista Estudos Feministas, Florianópolis, 26(1): e46069 